\title{
Para se repensar o pensamento da comunicação
}

\section{RESUMO}

Este artigo se propõe a problematizar, nos estudos da comunicação, os fundamentos não-lingüísticos, as sínteses incomunicáveis e as performances condicionantes da memória e da sensação que constroem a realidade do seu pensamento. É notável a insuficiência da linguagem, sendo portadora de articulações próprias, recortando fluxos, intensidades e ritmos em unidades descontínuas. Esta lógica da representação exige que estabeleçamos em nossas idéias as mesmas distinções que percebemos haver entre objetos e relações. Antes de se pensar em objeto, em intersubjetividade ou em fenômenos da comunicação, por exemplo, cabe imaginar o pensamento como um transdutor de imagens, de memórias, de regimes semióticos e de fluxos a-lingüísticos. Seria preciso repensar o pensamento da comunicação para além dos processos comunicacionais ou semiósicos.

\section{- PALAVRAS-CHAVE}

- pensamento

- memória imagem

\section{ABSTRACT}

This article proposes to discuss, studies of Communication, of a non-linguistic basis, the incommunicable syntheses and the conditioning performances of the memory and the sensation that construct the reality of its thought. The insufficience of language is notable because it cut flows and intensive rhythms in merely discontinous units. This logic of representation demands that we stabilish in our ideas the same distinctions that we perceive to have between objects and relations. Before thinking about object, intersubjetivicty or the phenomenon of communication, for example, is important to imagine the thought as a transducer of images, semiotics, memories, regimes and the-linguistic flows. It would be necessary to rethink the thought of communication beyond the communicational or semiosic processes.

\section{KEY WORDS \\ - thought \\ - memory \\ - image}

abemos que a realidade sensível se nos apresenta em sua impenetrabilidade ao nosso pensamento. Tentamos, através deste artifício imaginativo, domar infinitos movimentos que são absolutamente estranhos e rebeldes aos modos de operação do pensar. Ao que nos parece, o pensamento se constrói, contudo, como um exercício paradoxalmente inseparável da dinâmica das sensações. A estas nós remetemos imagens, abstrações, relações e lógicas, criadas para lhes dar alguma forma estável e, por meio das convenções lingüísticas, um sentido compartilhável, comunicável.

Há, entre muitas, uma idéia bastante insólita a respeito da obscura gênese do pensamento. Esta hipótese é apresentada por Michel Foucault, em um de seus primeiros textos. Ele nos diz que aprendemos a pensar porque o homem desenvolveu uma aptidão mnemônica para se lembrar dos seus sonhos. A explicação que ele nos dá é a de que os sonhos possuem uma dinâmica plástica e imaginativa. Isto quer dizer que a imaginação no sonho é uma tarefa absolutamente criativa. Assim pensado, é ao sonho que todo ato de imaginação remete.

\section{A língua, atada aos seus problemas intrínsecos, é forçada a figurar, a metaforizar, para exprimir forças e movimentos que não se circunscrevem sob o sistema lingüístico.}

O sonho não é somente uma modalidade da imaginação, ele é a sua condição primeira. Foucault afirma que foi no trabalho dinâmico da imaginação onírica, no caráter de seu movimento, engendrado pelo sonhar, que nasceu a nossa aptidão para conectarmos imagens numa progressão, com um certo ritmo distinto dos ritmos da percepção e da memória, quando estamos em vigília. Quando a consciência, no mundo já constituído pelas percepções, tenta re-apreender esse movimento, ela o interpreta em termos de encadeamentos lineares de imagens, que vão sendo injetadas de sentido. O sonho imagina, cria imagens, e a percepção, apenas as reconhece. Concluindo, Foucault assinala: "A frase (lingüística) se oferece, de imediato, com um sentido trivial: os caminhos da 
percepção estariam fechados ao sonhador, isolado pelo desabrochar interior de suas imagens." (FOUCAULT: 2002, p. 127-130)

De um modo diferente de Foucault, Gilles Deleuze também enfatiza que o pensamento tem, por sua própria gênese, uma imagem. Pensa-se imaginando um mundo formado por múltiplos elementos isolados e finitos e no qual adquirem contornos calculáveis, formas identificáveis e durações mensuráveis. O que o nosso pensamento tradicional pressupõe como condição primeira a imagem de um sujeito, dotado de uma consciência e de um olhar fixo, perspectívico, sempre imobilizado por uma lógica de binarizações e de compartimentações objetivas, hierárquicas e articuláveis.

\section{É a individualização no} pensamento "transcendente" 0 artifício mental pelo qual se injeta um sentido a partir da
identidade.

Ora, isso significa que, quando percebemos e pensamos o mundo, quase sempre nos valemos de imagens mentais, de afecções que são dotadas de forma, de contorno, de espessura, de medida, de substância, de mobilidade, etc. Essa realidade percebida, produzida por nossos estados vividos, porém, precisa coincidir com um modo de organizar o pensamento que, para se orientar e se desenvolver, imagina uma lógica relacional, uma ordem, uma subjetividade e uma contrapartida objetiva.

Por sua vez, a linguagem, sendo portadora de articulações próprias precisa, para ela se efetivar, de que recortemos os fluxos contínuos da existência em unidades descontínuas, "discretas", do signo. São tais descontinuidades as palavras, as frases, as idéias de grandeza, as imagens formadas, etc. Ela exige, deste modo, que estabeleçamos entre as nossas idéias, as mesmas distinções e a mesma descontinuidade que supostamente percebemos haver entre os objetos materiais. A língua, atada aos seus problemas intrínsecos, é forçada a figurar, a metaforizar, para exprimir forças e movimentos que não se circunscrevem sob o sistema lingüístico, que nem sequer se restringem a um regime de signos e que, igualmente, se esquivam à memória e à percepção. Estas, de sua parte, facilmente nos convencem de que vivemos uma realidade que é urdida por relações entre fenômenos. Este modo fenomênico de pensar é, porém, absolutamente incapaz de pensar, por exemplo, a indivisibilidade do ato ou as transiências intensivas do Tempo.

Foucault e Deleuze também nos alertaram para um fato deveras intrigante, que envolve a nossa realidade vivida e que afeta a realidade do pensamento: o quanto a nossa linguagem é atravessada por todo um modo de ver, por uma visualidade. Eles assinalam que a relação, ao mesmo tempo simbiótica e dicotômica entre o olhar e a linguagem, condiciona a maioria dos nossos modos de imaginar, de lembrar, de sentir, de pensar, de criar, etc.

O ato de ver mentalmente enquanto se está pensando tem sido uma espécie de recurso que, ao longo processo histórico de construção do pensamento, toma o domínio do sentido da visão como o próprio paradigma do conhecimento, deste modelo que sempre nos mantém nos limites e na inércia de um horizonte espacial e homogêneo.

\section{A transcendência e a imanência no pensamento da comunicação}

Vale perseverar, neste momento da discussão, recordando que Gabriel Tarde (2003) se preocupava muito mais com a ação recíproca entre os elementos do que com a sua natureza íntima, essencial. É que para ele não havia nada no universo senão conexões que se compõem e que também nunca uma coisa seria separável de suas acoplagens com o mundo. A sua imagem das maquinações de forças - e não só de coisas - que compõem o real remetem-se ao pensamento da individuação, ou da hecceidade, imaginada anteriormente por Duns Scott, filósofo que viveu entre os séculos XIII e XIV. A inquietação de Scott voltava-se para o questionamento do princípio de pensamento preocupado em destacar coisas, pessoas, valores, sujeitos e objetos, individualizados por meio de nomes próprios, de seus predicados, atributos, propriedades, etc.

É a individualização no pensamento "transcendente" o artifício mental pelo qual se injeta um sentido a partir da identidade. O que este recurso do pensar desconsidera, no entanto, são os movimentos não-identificáveis, que nos fazem e que nos afetam. Individualizar é operar, por meio de um recorte imagético abstrato, unidades materiais formadas por suas supostas características e naturezas. O pensamento das hecceidades, ao contrário, pressupõe a "individuação" (e não individualização), que evita olhar para as coisas e tenta imaginar ritmos, fluxos, cópulas, velocidades, transiências. A necessidade de se pensar em termos de hecceidades é que, antes de se deter na matéria e na forma, prefere deslizar entre estas, imaginando o mundo como um amplexo maquínico de ritmos heterogêneos.

A realidade que apreendemos perceptivamente é, em suma, o resultado de uma complexidade infinita: sob uma aparente uniformidade, se encontra uma diversidade. Trata-se, por fim, de uma agitação, de uma realidade inquieta que subsiste/insiste por trás da percepção do vivido, tal como uma intempestividade, uma realidade feita de tempos "invivíveis" e, claro, incomunicáveis. O que nos parece imóvel, na realidade, está repleto de movimentos recomeçantes e 
de ritmos continuamente dobrados uns nos outros. Recorremos às idéias de Gabriel Tarde, uma vez que ele assinala que até mesmo os átomos, última unidade elementar que se acreditava ser homogênea, estável, se revela múltipla, e cuja diversidade interna executa movimentos de grande imprevisibilidade. As suas palavras nos explicam melhor: "Sob a calma aparência que a percepção nos dá, um turbilhão se diz, num ritmo vibratório, algo infinitamente complicado." (TARDE: 2003, p. 11). Como antecipara o autor, a realidade linear e seqüencial da nossa consciência tem como origem, entretanto, uma singularidade prodigiosamente improvável, uma coincidência impossível de movimentos múltiplos, ao mesmo tempo, distintos e semelhantes: paradoxais. (TARDE: 2003, p. 70).

\section{Em Fernando Pessoa uma intrigante concepção da imagem da personalidade e de como esta precisa ser recriada por experimentações de uma despersonalização imaginativa da subjetividade.}

Para o pensamento representacional, o mundo nos é dado "fenomenalmente". Percebemos e abstraímos uma multitude de elementos, de formas e de relações. Nessa realidade que se representa a partir de um presente vivido, as coisas percebidas e lembradas passam a encobrir, contudo, irrefreáveis movimentos que se compõem de outros movimentos céleres - os virtuais - absolutamente irredutíveis à percepção. Mas eis que a evidência sensitiva contradiz, aparentemente, a concepção do Tempo como máquina de forças, como potência imaterial que desconhece a Forma, pois vemos efetivamente coisas e distinguimo-nos a nós mesmos como uma coisa em relação a outras.

O pensamento experimental de autores como Scott, Spinoza, Nietzsche, Tarde, Bergson, Pessoa, Blanchot, Deleuze, Foulcault e Guattari, tem em comum a idéia de que, antes de tentar representar, mensurar ou espacializar o Tempo, é preciso descrevê-lo como uma máquina de ritmos e de forças incorporais, simplesmente intensivos, que se acoplam e geram muitos outros movimentos, dentre estes aqueles que chamamos de sensíveis. A realidade do Tempo, pensada como imaterial, apenas potencial - ou processual possui uma dinâmica que não se parece, em nada, com a realidade do nosso mundo espacial, da percepção e da linguagem. Enquanto percebemos formas e exprimimos estados vividos, um mar de forças agitadas por tempestades moleculares, em perene fluxorefluxo, encavala ritmos que nem sequer sentimos, mas que são o motor das sensações. Tamanho acoplamento de ritmos se torna sensível apenas quando ganham velocidades que nosso organismo - ele mesmo uma síntese de ritmos variados - alcança apreender como duração perceptiva, por meio de várias performances de memória.

Foram principalmente tais autores que ousaram investir na apreensão conceitual, por experimentações do pensamento, de uma face virtual, "puramente" intensiva, da realidade. Esta seria imaginada em sua transiência íntima, heterogênea e imprevisivelmente criativa. Em suma: enquanto o pensamento transcendental escreve sobre coisas, objetos, signos ou fenômenos, o pensamento a favor da imanência pretende conceber imagens que nos remetam ao problema das intensidades, do movimento, dos fluxos, ritmos e afetos do Tempo.

Ora, o pensamento só poderá existir na condição de um investimento de imaginação criativa, de encontrar um princípio de criatividade ao pensamento, que promova um modo de se pensar criativamente. E tal vontade criativa somente se dará ao se fugir do pensamento como mero exercício da recognição: isto significa "problematizar". Pensar, enfim, é criar, porque é o que poderá fazer nascer um problema que ainda não existe, ao invés de simplesmente representar o que já está dado. A partir das idéias de Henri Bergson (1999), o pensamento terá uma chance de ultrapassar o pensamento representacional e passará a investir na recriação de um mundo inteiramente "problemático". Pensar, segundo Bergson, não é resolver uma questão com respostas, mas experimentar, criar um campo de problemas. Problemas esses que não param, contudo, de deslocar-se e de disfarçarem-se a si mesmos. Esta iniciativa faz do pensar o pensamento não como uma questão com respostas, mas como um campo criativo e experimental de problemas.

\section{0 contágio e a despersonalização no pensamento da comunicação}

Precisamos aceitar, antes de reportar à comunicação uma suficiência para dar conta da dinâmica social, que é nas trivialidades dos hábitos de convivência que certos gestos indizíveis acabam por se firmar, assumindo um papel de "disparadores", de catalisadores, que nos contagiam, por afeto, para aquém dos tempos extensivos da comunicação. Em suma, há forças intensivas que, antes de serem comunicáveis ou a despeito de todo o regime "atualizado" da comunicação, são simplesmente "contagiosas". Uma importante acepção que Gilles Deleuze dá à palavra "contágio" vem agora nos acudir. Não é a comunicação entre pessoas que interessa ao autor, mas sim o encontro com o que elas fazem, com as suas atitudes, gestos, pensamentos, afetos, etc. Em toda a gama de 
coexistência coletiva, seria preciso exercitar essa capacidade de capturar, por exemplo, um gesto, um ritmo, um pensamento poético, um "charme", mesmo antes que se efetue qualquer significação. Deleuze assim aponta o efeito indelével do contágio:

[...] percebendo alguém com quem nos ajustamos, alguém que nos ensina algo, que nos abre, nos desperta, e nós nos tornamos sensíveis a uma certa emissão de sinais. Nós os recebemos ou não, mas nós nos tornamos abertos a eles. (DELEUZE: 2003, p. 24).

Qualquer comunicação ou relação pode, deste modo, passar pelos encontros "incomunicáveis" com pessoas que estão em ressonância com o que se está fazendo, e assim por diante. É um tipo indeterminado de contato imanente, no qual se podem criar relações imperceptíveis com pessoas imperceptíveis, com uma linguagem, uma pré-linguagem, ou mesmo um afeto não lingüístico. São esses modos de contágio que ultrapassam os tempos "dramáticos", fenomenológicos, das relações entre pessoas e que se realizam, seja em qualquer circunstância social. É, de fato, muito comum nos encontrarmos com pessoas que, pelo exemplo de sua própria atividade, estimulam o que há de ativo em nós, que nos atraem e nos agitam, nos afetam e nos impelem, de modo imprevisto, a outras ações. Por sua vez, nossas ações também estarão imprevisivelmente abertas e potencialmente contagiantes.

Encontramos, por fim, em Fernando Pessoa uma intrigante concepção da imagem da personalidade e de como esta precisa ser recriada por experimentações de uma despersonalização imaginativa da subjetividade. Esta idéia de Pessoa é aqui re-endereçada aos nossos questionamentos da imagem do Eu, a partir da possibilidade da ficção experimental de um heterônimo no pensamento da comunicação. Isto porque não é a subjetividade que pensa, que sente ou que cria como um indivíduo identitário: pensa-se, sentese e cria-se em nós. Esta idéia de uma necessária despersonalização da personalidade pode alcançar aqui, mais do que um princípio epistemológico, a dimensão de uma micro-política, de uma ética da existência.

Finalizando: para Gilles Deleuze, o pensamento ocidental deveria se investir de poderes libertários para despir-se de suas imagens abstratas, encorajando a proposta de um pensamento destituído de imagem. Para tanto, ele prioriza a questão da impensável física de forças que faz o pensamento viver e se criar. O autor adota a defesa de um pensamento que esteja em imediata correlação, não com uma forma, seja do mundo ou do sujeito, mas sim com forças, com potências não-formadas de um cosmos de fluxos energéticos. Afinal, há inomináveis movimentos ínfimos e pequeninas vibrações das quais se elevam eventos absolutamente impensáveis à realidade meramente recognitiva do pensar, à pseudo-realidade da percepção, do signo e da comunicação. Famecos

\section{REFERÊNCIAS}

BERGSON, Henry. Matéria e Memória: ensaio sobre a relação do corpo com o espírito. São Paulo: Martins Fontes, 1999.

DELEUZE, Gilles \& GATTARI. O que é a filosofia? São Paulo: Ed. 34, 1997.

GIL, José. Fernando Pessoa ou a metafísica das sensações. Lisboa: Relógio D'água Editores, 1997.

TARDE Gabriel. Monadologia e Sociedade. Petrópolis: Vozes, 2003. 